\title{
Potential Role of Selected Lichens Collected from India as Antifungal Agents against Dermatophytes
}

\author{
N.S. Ravichandran* and S. Daya Pauline \\ Department of Microbiology Sree Mookambika Institute of Medical Sciences, \\ Kulasekharam, Tamil Nadu, India \\ *Corresponding author
}

\section{Keywords}

Dermatophytosis, antifungal activity, Lichen extracts

Article Info

Accepted:

07 March 2019

Available Online:

10 April 2019
A B S T R A C T

Fungal infections which include Dermatophytosis are one among the most common communicable disease in the world. Dermatophytes are a group of fungi which cause infection on skin, hair and nails and these fungi do not infect mucosal surfaces. The study was aimed at evaluating the antifungal activity of diethyl ether, methanol and acetone extract of selected lichens Usnea perplexans Stirton, Usnea spinocula Stirton, Usnea subsordiata Stirton, Ramalina conduplicans Vainio, Roccella montagnei Bel emend, Aswath against dermatophytes, Aspergillus flavus and Candida albicans. The invitro antifungal activity was performed by disk diffusion method and broth tube dilution method. All the three extracts of the selected lichens showed antifungal activity against Dermatophytes, Aspergillus flavus and Candida albicans. The activity varied depending upon the lichen and the extract.

\section{Introduction}

Superficial fungal infections particularly those involving the skin and mucosal surfaces constitute a serious problem, especially in tropical and subtropical developing countries (1). Dermatophytes have been reported to be potentially pathogenic (2) and are directly connected with the skin fungal infections. They are a group of closely related keratinophilic fungi that invade keratinized humans and animal tissues such as skin, hair and nails causing Dermatophytosis. Dermatophytes consist of three genera Trichophyton, Microsporum, and Epidermophyton (3). Unlike other fungal infections, cutaneous mycosis has been considered important in which host immune responses are highly evoked resulting in severe pathologic changes, which are extended deeper into epidermis as well as hair and nails. Such fungal infections are mainly caused by Microsporum species (4). Humid weather, over population and poor hygienic condition induce the growth of dermatophytes and thereby dermatophytosis.

The drugs that are in use to cure dermatophytosis exhibit several side effects and have limited efficiency (5). Further with allopathic drugs, the problem of drug resistance and drug toxicity cannot be ruled 
out. Therefore, there is a distinct need for the discovery of new, safer and more effective antifungal agents.

The hunt for novel natural bioactive compounds as a foundation to a new drug discovery is getting greater awareness as formerly reliable standard drugs become less effective against the emerging new strains of multi drug-resistant pathogens (6). The challenge for today's pharmaceutical industry lies in this discovery of such natural bioactive compounds and its development (7). Plants and their preparations have been used as medicines against infectious diseases. Similar to higher plants, lichens were used since antiquity as natural drugs.

The history of lichens and its biological activity date back from the period after World War II. Lichens, together with some marine organism and frog venom, are important sources of biologically active compounds (8). These organisms produce secondary metabolites and many of them are known for presenting biological and/or pharmacological activities. About 350 secondary metabolites have been known from lichens and around 200 have been subjected to isolation and characterization. Out of all the secondary compounds extracted from lichens, the best known is Usnic acid, an antibiotic with phenol structure (9). Lists of the antibacterial and antifungal activities of lichen compounds and lichens against bacteria and fungi can be found in a review and a book $(10,11)$.

In this study we have evaluated the. The selected lichen extracts (Acetone, Methanol and ethanol) produced antifungal activities against Aspergillus flavus, Candida albicans Microsporum gypseum, Trichophyton mentagrophytes, and Epidermophyton the most common aetiological agent of dermatophytosis.
To evaluate the antifungal activity of certain lichen extracts of Usnea perplexans Stirton, Usnea spinocula Stirton, Usnea subsordiata Stirton, Ramalina conduplicans Vainio, Roccella montagnei Bel emend, Aswath against dermatophytes and Candida albicans

\section{Materials and Methods}

\section{Study design: Descriptive study}

Study Setting: Department of Microbiology Sree Mookambika Institute of Medical Sciences, Kulasekharam

\section{Collection of lichens}

Lichens specimens were collected from Kodayar of Western Ghats, Kanyakumari District, during summer season. Identification of collected lichens collected lichens were sent to NBRI Lucknow and identified by Dr. Upreti.

\section{Preparation of the extracts of lichens}

Collected lichens were cleaned of extraneous material, dried at room temperature and ground into a coarse powder. 100gms of the coarse powder was subjected to successive extraction with the three solvents namely diethyl ether (non polar), acetone (mid polar) and methanol (highly polar) by hot percolation method. The extractions were carried out for a period of 72 hours at a temperature not exceeding the boiling point of the solvents. At the end of the extraction, the respective solvents were concentrated by evaporation under reduced pressure. The crude extracts were then transferred to small glass bottles and placed in a desiccator containing fused calcium chloride. These crude extracts were redissolved in respective solvents and the antifungal activity was carried. 
Preliminary phytochemical analysis of selected Lichens extract

All the three extracts of the selected were subjected to preliminary phytochemical analysis for detection of secondary metabolites following standard procedures.

\section{Antifungal susceptibility test}

In-vitro susceptibility testing was done for all fungal isolates to look for their antifungal susceptibility. This was done by standard broth dilution technique (NCCLS M-38A, 2002).

\section{Preparation of fungal inoculum}

Three dermatophytic fungi were taken for this study. Dermatophytic fungi taken were Trichophyton mentagrophytes, Trichophyton rubrum, Microsporum canis, Microsporum gypseum and Epidermophyton floccosum. The selected standard dermatophytes were grown on sabouraud dextrose agar (SDA). Twenty one day old culture of dermatophytic fungi was scraped with sterile scalpel and macerated with $10 \mathrm{ml}$ of sterile distilled water. The suspension was adjusted spectrophotometrically to an absorbance of 0.600 at $450 \mathrm{~mm}$. This suspension was used as inoculum for MIC and MFC. Each tube with media was inoculated with $20 \mu \mathrm{l}$ of fungal suspension.

\section{Determination of Minimal inhibitory concentration (MIC)}

Susceptibility testing was determined by broth macro dilution method. MIC was analyzed by incorporating various concentrations of lichen extracts. The SD broth was prepared in a tube. The plant leaf extracts or fractions were diluted serially with dimethyl sulfoxide (DMSO). The diluted extracts were added to the SD broth and made up to $2 \mathrm{ml}$ volume.
$20 \mu 1$ fungal inoculums were added to the extract containing broth. Positive controls were also maintained with known antifungal agents. Negative control was maintained with DMSO. All the tubes were incubated at $30^{\circ} \mathrm{C}$ and were read at every two-day up to 14 days of incubation. The MICs were determined by visual observation for the inhibition of growth and were compared with that of the control (positive and negative) tubes.

\section{Results and Discussion}

Antifungal susceptibility testing is a dynamic field of medical mycology (12). Development and standardization of antifungal susceptibility tests have shown remarkable progress in the field of medical mycology. This is the first report being presented on the antifungal activity of Lichens collected from Western Ghats. The intensity of the antifungal activity was dependent upon the sort of the extract, its concentration and the tested microorganism. Similar differences were also noticed by other investigators (13). Preliminary phytochemical analysis tabulated in table 1 showed the presence of Phenols, reducing sugars, flavonoids, Saponin, quinones and tannins in all the three extracts of the selected lichens. In addition to these phytoconstituents, Steroids were found in all the lichens extract except in the acetone extract of Usnea subsordiata stirton and Ramalina conduplicans Vainio. The ethanolic extract of Usnea perplexans Stirton did not showed the presence of glycosides while all the other solvent extracts of the selected lichens showed glycoside presence. Alkaloid was also present in all the three extracts of the selected lichens with the exception of methanolic extract of Ramalina conduplicans Vainio.

Antifungal activity of the selected lichens was examined qualitatively and was assessed by the presence or absence of inhibition by disc 
diffusion method for Candida albicans and macro broth dilution method for all the tested fungi (Table 2). Amphotericin was used as standard at a concentration of $5 \mathrm{mg} / \mathrm{ml}$. The antifungal assay revealed that the selected lichens showed a potent antifungal activity in a concentration dependent manner. The antimicrobial activity of ethanolic extract of the Indian Usnea subsordiata stirton collected from Western Ghats showed minimum MIC 20 against Candida albicans and A.flavus and maximum MIC 320 against E. floccosum. Methanolic extract of the same showed minimum MIC 160 against T. mentagrophytes and E. floccosum and maximum MIC 640 against Candida albicans. Acetone extract of Usnea subsordiata stirton showed minimum MIC 20 against E. floccosum and Candida albicans, maximum MIC 320 against A.flavus, T. mentagrophytes, M. gypseum.

The antimicrobial activity of the ethanolic and methanolic extract of Usnea perplexans Stirton showed minimum MIC 160 against A.flavus T. mentagrophytes and E. floccosum. A maximum MIC of 320 against $M$. gypseum and Candida albicans was observed in the ethanolic extract of Usnea perplexans Stirton while the methanolic extract of Indian Usnea perplexans Stirton maximum MIC 640 against M. gypseum. Acetone extract of Usnea perplexans Stirton showed minimum MIC 160 against $E$. floccosum maximum MIC 640 against $M$. gypseum. The ethanolic extract of Indian Usnea spinocula Stirton showed minimum MIC 160 against all the tested fungi. Methanolic extract of Indian Usnea spinocula Stirton showed minimum MIC 160 against T. mentagrophytes and E. floccosum, $M$. gypseum and, A.flavus maximum MIC 640 against $C$. albicans. Acetone extract of Indian Usnea spinocula Stirton showed minimum MIC 160 against $E$. floccosum and $M$. gypseum, maximum MIC 320 against T. mentagrophytes, A.flavus and C. albicans.
Ethanolic extract of Ramalina conduplicans Vainio showed minimum MIC 160 against $T$. mentagrophytes and E. floccosum, maximum MIC 320 against A.flavus, M. gypseum and $C$. albicans. Methanolic extract of Indian Ramalina conduplicans Vainio, showed minimum MIC 160 against E. floccosum and, A.flavus maximum MIC 320 against $T$. mentagrophytes, $M$. gypseum and C. albicans. Acetone extract of Indian Ramalina conduplicans Vainio, showed minimum MIC 160 against $E$. floccosum and M. gypseum, maximum MIC 320 against $T$. mentagrophytes, A.flavus and C. albicans. The antimicrobial activity of ethanol extract of Indian Roccella montagnei Bel emend, Aswathi showed minimum MIC 160 against A.flavus and E. floccosum and M. gypseum maximum MIC 320 against, $T$. mentagrophytes and C. albicans. Methenolic extract of Indian Roccella montagnei Bel emend, Aswathi, showed minimum MIC 160 against $T$. mentagrophytes and E. floccosum and, maximum MIC 320 against A.flavus, $M$. gypseum and $C$. albicans. Acetone extract of Indian Roccella montagnei Bel emend, Aswathi showed minimum MIC 160 against E. floccosum, maximum MIC 320 against A.flavus T. mentagrophytes, M. gypseum and C. albicans.

Pure Usnic acid showed minimum MIC 160 against E. floccosum and maximum MIC of 320 in the rest of the other tested fungi. Usnic acid is one of the most common and investigated lichen compounds. Its antimicrobial, antiprotozoal, antiviral, antiproliferative, anti-inflammatory, analgesic, antipyretic, and anti-tumour activities as well as some other properties such as UV protection, allergen, and toxicity have been summarized in two recent reviews. Among the lichen substances, the most widely distributed and the most extensively investigated one is Usnic acid $(14,15)$. 
Table.1 Preliminary phytochemical analysis of the selected lichens

\begin{tabular}{|c|c|c|c|c|c|c|c|c|c|c|}
\hline Lichens & 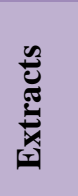 & $\frac{n}{\mathscr{0}}$ & 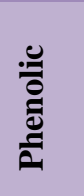 & 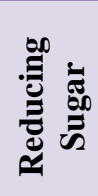 & $\begin{array}{l}\frac{n}{0} \\
\frac{0}{0} \\
\frac{\pi}{2} \\
\frac{\pi}{x}\end{array}$ & 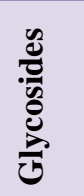 & 音 & 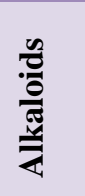 & 离 & .气气 \\
\hline \multirow{3}{*}{$\begin{array}{c}\text { Usnea subsordiata } \\
\text { stirton }\end{array}$} & $\mathrm{E}$ & + & + & + & + & + & + & + & + & + \\
\hline & $\mathrm{M}$ & + & + & + & + & + & + & + & + & + \\
\hline & A & - & + & + & + & + & + & + & + & + \\
\hline \multirow{3}{*}{$\begin{array}{l}\text { Usnea perplexans } \\
\text { Stirton }\end{array}$} & $\mathrm{E}$ & + & + & + & + & - & + & + & + & + \\
\hline & M & + & + & + & + & + & + & + & + & + \\
\hline & A & + & + & + & + & + & + & + & + & + \\
\hline \multirow{3}{*}{$\begin{array}{l}\text { Usnea spinocula } \\
\text { Stirton }\end{array}$} & $\mathrm{E}$ & + & + & + & + & + & + & + & + & + \\
\hline & M & + & + & + & + & + & + & + & + & + \\
\hline & A & + & + & + & + & + & + & + & + & + \\
\hline \multirow{3}{*}{$\begin{array}{l}\text { Ramalina } \\
\text { conduplicans } \\
\text { Vainio }\end{array}$} & $\mathrm{E}$ & + & + & + & + & + & + & + & + & + \\
\hline & M & + & + & + & + & + & + & - & + & + \\
\hline & A & - & + & + & + & + & + & + & + & + \\
\hline \multirow{3}{*}{$\begin{array}{c}\text { Roccella } \\
\text { montagnei Bel } \\
\text { emend, Aswathi }\end{array}$} & $\mathrm{E}$ & + & + & + & + & - & + & + & + & + \\
\hline & M & + & + & + & + & + & + & + & + & + \\
\hline & $\mathbf{A}$ & + & + & + & + & + & + & + & + & + \\
\hline
\end{tabular}

+ - Present; - - Absent; E - Ethanol; M- Methanol; A- Acetone

Table.2 Antifungal activity of ethanol, methanol and acetone extract of selected lichens

\begin{tabular}{|c|c|c|c|c|c|c|}
\hline \multirow{2}{*}{$\begin{array}{l}\text { Name of the } \\
\text { lichens }\end{array}$} & \multirow{2}{*}{ 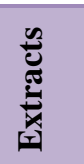 } & \multicolumn{5}{|c|}{ MIC in microgram } \\
\hline & & A.flavus & T.mentagrophytes & Epidermophyton & $\begin{array}{l}\text { Microsporum } \\
\text { gypseum }\end{array}$ & C.albicans \\
\hline \multirow{3}{*}{$\begin{array}{c}\text { Usnea } \\
\text { subsordiata } \\
\text { stirton }\end{array}$} & $\mathrm{E}$ & 20 & 80 & 320 & 40 & 20 \\
\hline & M & 320 & 160 & 160 & 320 & 640 \\
\hline & A & 320 & 320 & 160 & 320 & 160 \\
\hline \multirow{3}{*}{$\begin{array}{c}\text { Usnea } \\
\text { perplexans } \\
\text { Stirton }\end{array}$} & $\mathrm{E}$ & 160 & 160 & 160 & 320 & 320 \\
\hline & M & 320 & 160 & 160 & 640 & 320 \\
\hline & A & 320 & 320 & 160 & 640 & 320 \\
\hline \multirow{3}{*}{$\begin{array}{c}\text { Usnea } \\
\text { spinocula } \\
\text { Stirton }\end{array}$} & $\mathrm{E}$ & 160 & 160 & 160 & 160 & 160 \\
\hline & M & 160 & 160 & 160 & 160 & 640 \\
\hline & A & 320 & 320 & 160 & 320 & 320 \\
\hline \multirow{3}{*}{$\begin{array}{c}\text { Ramalina } \\
\text { conduplicans } \\
\text { Vainio }\end{array}$} & $\mathrm{E}$ & 320 & 160 & 160 & 320 & 320 \\
\hline & M & 160 & 320 & 160 & 320 & 320 \\
\hline & A & 320 & 320 & 160 & 160 & 320 \\
\hline \multirow{3}{*}{$\begin{array}{c}\text { Roccella } \\
\text { montagnei Bel } \\
\text { emend, } \\
\text { Aswathi }\end{array}$} & $\mathrm{E}$ & 160 & 320 & 160 & 160 & 320 \\
\hline & M & 320 & 160 & 160 & 320 & 320 \\
\hline & A & 320 & 320 & 160 & 320 & 320 \\
\hline Usnic acid & & 320 & 320 & 160 & 320 & 320 \\
\hline
\end{tabular}


After the evaluation of the results, the acetone extract of Usnea subsordiata stirton showed the highest inhibitory activity even at minimum MIC among the other lichen extracts against the tested fungi. It may due to the presence of the Usnic acid in the selected lichens which showed a potent antifungal activity.

In conclusion, the above results demonstrate that the antifungal activity of the selected lichens against dermatophytes, $C$ albicans and A flavus correlates with the earlier reports on the antimicrobial activity of the lichens and Usnic acid, the active component widely distributed in lichens. The obtained results showed that the tested lichen extracts and lichens acids showed a significant antimicrobial activity relative to the tested fungi, which could be of significance in therapy human, animal and plant diseases. Further studies should be done to search new compounds from lichens that exhibit strong antimicrobial activity.

\section{References}

1. Stern, RS (1996). Managed care and treatment of skin diseases: dermatologists do it less often. Arch. Dermatol. 132, 776-780.

2. Shtayeh, MSA and Arda HM (1985). Incidence of dermatophytosis in Jordan with special reference to tinea capitis. Mycopathol. 92, 59-62.

3. Keyvan Pakshir, Leila Bahaedinie, Zahra Rezaei, Manuchehr Sodaifi, Kamiar Zomorodian. In vitro activity of six antifungal drugs against clinically important dermatophytes. Jundishapur Journal of Microbiology (2009); 2(4): 158-163.

4. Rai, MK and Vasanth S (1995). Laboratory evaluation of sensitivity of three keratinophilic fungi to some vicolides. Hind. Antibio. Bull. 37, 1-4.

5. Weitzman, I, Summerbell RC. The dermatophytes. Clin Microbiol Rev 1995, 8:240-59.

6. Muller, K. 2001. Pharmaceutically relevant metabolites from lichens. Applied Microbiol. Biot., 56: 9 -16.

7. Behera, BC, Verma N, Sonone A, Makhija U (2005). Antioxidant and antibacterial activities of lichen Usnea ghattensis in vitro. Biotechnol Lett. 27: 991-995.

8. Barnes, J (2000). Pharmacognosy in the 21 st century. Pharm J. 264: 701-703.

9. A.P. Podterob (2008). Chemical composition of lichens and their medical applications. Pharmaceutical Chemistry Journal. Vol 42. Pp 32 -38.

10. Huneck, S. (1999). The significance of lichens and their metabolites. Naturwissenschaften 86, 559 -570.

11. Huneck, S. (2001), New results on the chemistry of lichen substances. In: Progress in the Chemistry of Organic Natural Products, 81 (Herz W., Falk H., Kirby G. W., and Moore R. E., eds.). Springer, Wien, New York, 224 -230.

12. Sevtap, A. Current status of antifungal susceptibility testing methods. Med Mycol. 2007; 45: 569-87.

13. Ranković, B., Mišić, M., Sukdolak, S., Milosavljević D., Antimicrobial activity of the lichen Aspicilia cinerea, Collema cristatum, Ochrolechia androgyna, Physcia aipolia and Physcia caesia. Ital. J. Food Sci, Vol.4, No.19, 2007, pp.461469.

14. Cocchietto, M., Skert N., Nimis P. L., and Sava G. (2002). A review on usnic acid, an interesting natural compound. Naturwissenschaften 89, $137-146$.

15. Ingolfsdottir, K. (2002), Usnic acid. Phytochemistry 61, $729-736$.

\section{How to cite this article:}

Ravichandran, N.S. and Daya Pauline, S. 2019. Potential Role of Selected Lichens Collected from India as Antifungal Agents against Dermatophytes. Int.J.Curr.Microbiol.App.Sci. 8(04): 721-726. doi: https://doi.org/10.20546/ijcmas.2019.804.078 